\title{
We Feel, Therefore We Memorize: Understanding Emotions in Learning Mathematics Using Neuroscience Research Perspectives
}

\author{
Amran M. S., Bakar A. Y. A.* \\ Faculty of Education, Universiti Kebangsaan Malaysia, 43600, Bangi, Selangor, Malaysia
}

Received August 18, 2020; Revised September 29, 2020; Accepted October 19, 2020

\section{Cite This Paper in the following Citation Styles}

(a): [1] Amran, M. S., Bakar, A. Y. A. , "We Feel, Therefore We Memorize: Understanding Emotions in Learning Mathematics Using Neuroscience Research Perspectives," Universal Journal of Educational Research, Vol. 8, No. 11B, pp. 5943 - 5950, 2020. DOI: 10.13189/ujer.2020.082229.

(b): Amran, M. S., Bakar, A. Y. A. (2020). We Feel, Therefore We Memorize: Understanding Emotions in Learning Mathematics Using Neuroscience Research Perspectives. Universal Journal of Educational Research, 8(11B), 5943-5950. DOI: 10.13189/ujer.2020.082229.

Copyright $\mathrm{C} 2020$ by authors, all rights reserved. Authors agree that this article remains permanently open access under the terms of the Creative Commons Attribution License 4.0 International License

\begin{abstract}
Emotionally significant experiences tend to be well remembered in learning Mathematics in the classroom. Recent advances in neuroscientific methods have led to an increased understanding of the neural mechanisms underlying emotions in learning mathematics. The aim of this research is to use neuroscience research perspectives in classroom setting involving students' emotion in learning Mathematics and its relationship with memory. Therefore, this research examined how students' emotions in learning Mathematics and its relationship with their memory using mixed-method design. Data from survey $(n=644)$ and interview informants $(n=6)$ indicated positive emotions (enjoyment, hope, pride) negative emotions (shame, anger, boredom, anxiety) and memory. Students who accurately identified positive emotions indicated they were more likely to learn Mathematics compared to negative emotions, and findings indicated a strong, positive correlation between positive emotions and memory. Qualitative findings indicated that students who are more likely prefer positive emotions in learning could lead to better memory compared to negative emotions. Moreover, interview data showed that memory performance in Mathematics increased when teacher has embedded positive emotions through the use of humor in teaching, inspiring student with positive words and engaging student in classroom. This study supports neuroscience research findings that positive emotions influence students' memory in learning mathematics. Thus,
\end{abstract}

this study provides insight for teachers to emphasize the importance of positive emotions in learning mathematics as well as reduce negative emotions.

Keywords Emotions, Memory Mathematics, Neuroscience

\section{Introduction}

The emerging field of Educational Neuroscience aims to bring together biology, cognitive science, development, and education to create a strong research foundation for education [1-4]. This foundation requires a new approach to connect research and education with a two-way collaboration in which practitioners and researchers work together to formulate research questions and methods so that they can be connected to practice and policy. This area of transdisciplinary research is able to understand how students learn, enhance their cognitive ability, affective and behavioural from biological, physiological as well as psychological perspectives $[5,6]$. Therefore, the transdisciplinary research related to education and neuroscience have a significant value in explaining how brain works in teaching and learning and overcome students' problem in learning. One of the main issues in teaching and learning is students' emotional problems in 
learning Mathematics [7, 8]. Emotion plays an important role in stimulating cognitive especially memory to learn [9, 10]. The reason is that emotions in learning can affect brain regions such as the prefrontal cortex which is important for thinking and reasoning as well as the hippocampus that plays important roles in consolidation of information memory $[9,11,12]$. This information can increase the knowledge gap in educators to understand the role of emotion and its effect on student's brain and at the same time overcome the students' emotional problem in learning Mathematics [10, 13, 14].

Past research shows that Mathematics achievement problem is closely related to students' emotion in learning $[8,15,16,17]$. Students' emotional problem in classroom can be seen when students feel stressed while learning Mathematics because they are afraid to face the teachers who are too strict and serious when delivering lesson [18-20]. More problems arise when some teachers use autocratic approach in teaching, making the students fear the learning. Autocratic approach that is used in the class such as yelling, cussing and throwing inappropriate language which aims to discipline students in the classroom so that the lesson can be delivered well will exert negative effects on the students' emotions. This can make the students become anxious about learning Mathematics in the classroom. Students who have a lot of negative emotions will have a hard time to remember new things they learn in the class. Instead, they will remember all the bad things that have happened during the teaching process $[9,11]$.

Next, uninteresting and boring teaching methods cause the students to become uninterested in learning Mathematics [21,22]. This problem willcause students not focus on the class; and on the contrary, they will create chaotic atmosphere by disturbing their peers, skipping class and a lot more. Other than that, a teaching method that is not interactive and a one-way approach lead to students' negative emotional problem [23]. The reason is that students cannot express their knowledge and understanding through their participation in the class. In other words, students are not given the chance to express emotions and knowledge about Mathematics class because teacher focuses on delivering the learning content only. Consequently, teachers indirectly ignore student emotions in learning and they are not able to understand how memory works particularly in solving mathematical problem [37].

Students' difficulty in memorizing theories, formulae, logical and facts relating numbers make them acquire a negative perception towards learning Mathematics. It happens because students cannot relate the importance of Mathematics in their real life context. Abstract learning that does not account for students' life environment into consideration affects working memory role to save information in long term and short-term memory. The reason is that students' perception has direct relation with working memory for reasoning and solving Mathematics problems [8, 24, 37]. This is threatening the effectiveness of teaching process that influences students' achievement. It results in students' avoidance attitude towards learning Mathematics, Science stream class or even future careers that involve Mathematical application.

The discussion above addresses that emotional issue influences students' memory in learning Mathematics. From the discussion, emotion is the main aspect that should be given attention especially in teaching and learning process. Negligence towards emotional aspect in the classroom effects the memory ability and students' achievement in learning Mathematics. Therefore, this research examines students' emotions in learning Mathematics and its relation with memory. This research also uses educational neuroscience research input which explains and supports the role of emotions and memory from biological and psychological perspective. The result of the research showed that teacher plays an important role in understanding students' development from the perspectives of neuroscience, psychology and education in learning Mathematics.

\section{Literature Review}

Emotions can play a significant role in our lives because they have important functions. Emotion is the result of outer stimulus that interacts with subjective feelings, physiological reaction and behaviour $[18,25]$. There are several perspcetives to understand the situation and emotional changes $[19,26,27,38]$ which are: (1) subjective approach that can assess feelings and experiences that one have gone through and (2) understanding through behaviour, facial expression and gestural. This is align with a theory of how the mind interprets the verbal, written and teaching materials that are related to Mathematics could influence the brain and emotions to learn Mathematics [38]. In education context, both approaches are used to indicate students' emotions in understanding the role of emotions in learning process. There are a lot of past researches that explain about how emotion influences students' cognitive processes in learning Mathematics [20, 24]. Therefore, teaching style, teaching materials and teachers' character can have an impact on students' learning of Mathematics.

On the other hand, the objective approach through physiological reaction that includes electric and hemodynamic central nervous system (CNS) activities as the addition to the respond of autonomic nervous system (ANS) like heart rate, body temperature, and pulse are used to understand emotion procesing and its function towards brain $[19,28]$. There are a lot of neuroscience researches that highlight the role of emotion in influencing brain parts which are amygdala and prefrontal cortex [7, 29]. These parts can influence students' cognitive processes in 
classroom. The prefrontal cortex is the part of the brain that processes information for a high level of reasoning while the amygdala records emotions or situations in life $[29,7$, $11,12]$. From the findings of the neuroscience research, the researchers will discuss in more detail; the results of this study can be applied in the context of learning.

Cannon-Bard theory (1929) explained that emotions and physiological of the body undergo changes to adapt to the situations and that engaging in activities could plays a role in brain functioning [39]. It means that the pressure and tension towards emotion will exert effect on the brain psychologically and physiologically. There are two main parts, are Autonomic Nervous System (ANS) and 'hypothalamus - pituitary - adrenal', stimulating biochemical to react with the physiological and biological of the human brain. Autonomic Nervous System (ANS) functions to secrete Catecholamine hormone [11, 12]. Catecholamine hormone that is secreted from the brain regions of Locus Coeruleus and Adrenal Medulla acts as 'Flight or Fight' or 'fight' or 'abandon' in determining an environmentally responsible response. In other words, these responses will impact the students' behaviour in learning such as skipping class, disturbing classes and so on. Stimulation of these hormones affects concentration, working memory and long-term memory $[11,28]$. Hence, it can be understood that high negative emotion will produce Catecholamine hormone which will disturb human's biological and physiological functioning.

Meanwhile in the classroom context, when a student is not interested in paying attention to understand and concentrating on the lesson, it impacts the prefrontal cortex mainly involving the reasoning aspect, decision making and other process involved in Mathematics. Research [11] supports that emotional stress will make the students to become unable to process the learning information that will be delivered, but record all the negative emotions while learning Mathematics. The implication is that the negative emotions recorded by student in class will give bad experience for them to learn Mathematics. In other words, that experience influences the perception, interest and students' motivation to learn $[9,10]$. This problem may drag down students' academic achievement in Mathematics. Researchers show that learning environment has a relation with memory performance in learning Mathematics. It justifies the mechanism played by negative emotion problem in deterring the teaching and learning process in Mathematics [10, 14, 18].

The results of neuroscience studies on emotion and brain can be used to understand and support the result of this research. These inputs can close the gap of a teacher's knowledge relating to mind, emotion and students' cognitive aspect. The reason is that most of the teachers are lacking in the neuroscience background or courses relating to neuroscience in education. In other words, teacher cannot understand how emotion influences brain biological function and biochemical terms related to it, including significant neuroscience research result data. This limitation causes teacher to not understand the contribution from neuroscience researches in learning that can improve learning quality in the classroom $[1,2]$.

Moreover, neuroscience researches that relate emotions in teaching give implication towards the functions of brain biology, physiology and cognition [13, 28, 32]. However, there is a lack in past research that translates the neuroscience perspective in handling students' emotional problem that is discussed and explained from education perspective $[6,9]$. The reason is that a lot of past researches relating to neuroscience and education are discussed separately. This separated discussion causes the teachers to not be able to relate neuroscience research result to teaching and learning context. This research is an effort to show the importance of emotions in learning Mathematics and its relation with working memory. Research result discussion uses neuroscience perspective to support and highlight the importance of emotions in learning Mathematics and its relation to working memory.

\section{Materials and Methods}

This study used a mixed-method design which is quantitative for survey and qualitative for participants' interview. We collected survey data from 644 students across Malaysia, the selection of respondents is important to give feedback on the aspects of the study done. The research instrument used was a questionnaire to measure the emotions of Mathematic learners. The research instrument was adapted from Achievement Emotions Questionnaire (AEQ) [26] and Questionnaire of Memory (Q-MEM) [33]. This instrument is divided into four sections. Section A is a set of questions about the respondents' profile. Section B consists of 20 items that measure positive emotions that have three components namely emotion of enjoyment, hope and pride. Meanwhile, section C consists of 34 items that measure negative emotions of students consisting of four components which are anger, shame, boredom and anxiety. Lastly, section D measures memory in learning Mathematics. This questionnaire instrument was scored on a five-point Likert scale which is labelled as 5-Strongly Agree, 4-Agree, 3-Agree, 2-Disagree, and 1-Strongly Disagree. Pilot study showed that Cronbach's alpha value for each component for positive emotions; negative emotions and memory are greater than 0.70 (refer Table 1). This value indicates that this instrument has a high level of reliability.

In addition, this research used a qualitative approach and data was collected from four semi-structured individual interviews. Galletta (2013) guided the development on the interview protocol by building rapport with informants, effective phasing and timing of probing question. Interviews were conducted in the classroom, and it took approximately 45 minutes to record it. As 
exploratory, mixed-method study, the interview prompts were developed based on an analysis of student's quantitative response. Specifically, the interviews focused on collecting information about the foundations of positive emotions and factors that ignited positive emotions in learning Mathematics (refer Table 2). Framework guided the qualitative analysis, which researcher's synthesized explanation and discussion from the participants based on the categories that were identified [35]. We gathered both quantitative and qualitative data to highlight the main research questions and compared participants' responses to check for disconfirming evidence and discrepancies. Moreover, we triangulated data across participants to see the reliability and validity of the survey data, we used member check to verify and explore the meaning of participants' responses.

\section{Results and Discussion}

The results of the study are reported in three aspects namely: i) students' perception of positive and negative emotions in learning Mathematics, ii) the correlation between students' emotions and memory in learning Mathematics and iii) how emotions influence memory in learning Mathematics.

Figure 1 displays the descriptive analysis of positive emotions (enjoyment, proud and hope) and negative emotions (anger, shame, boredom and anxiety). The findings show positive emotional components are at moderate to high levels in enjoyment (mean $=3.28, \mathrm{SD}=$ 0.86 ), proud (mean $=3.20, \mathrm{SD}=0.82$ ) and hope (mean $=$ $3.38, \mathrm{SD}=0.85$ ). However, the negative emotional component shows a moderate to low levels in anger (mean $=2.04 ; \mathrm{SD}=0.77)$, shame $($ mean $=2.55 ; \mathrm{SD}=0.81)$, boredom (mean $=2.21 ; \mathrm{SD}=0.96)$ and anxiety (mean $=$ 2.98; $\mathrm{SD}=0.76$ ). Total overall mean for positive emotions is $3.06(\mathrm{SD}=0.73)$ which is higher than that of negative emotions which has a mean of $2.45(\mathrm{SD}=0.66)$. These results revealed that students prefer positive emotions embedded by teacher in teaching Mathematics class.

Table 1. Cronbach Alpha Coefficient of the Variables

\begin{tabular}{cccccc}
\hline \multicolumn{5}{c}{ VARIABLE } \\
\hline Positive Emotions & Cronbach's alpha & Negative Emotions & Cronbach's alpha & Memory & $\begin{array}{c}\text { Cronbach's } \\
\text { alpha }\end{array}$ \\
\hline Enjoyment & 0.913 & Anger & 0.822 & Working Memory & 0.714 \\
Hope & 0.890 & Shame & 0.873 & Procedural Memory & 0.769 \\
Proud & 0.820 & Boredom & 0.838 & & \\
& & Shame & 0.940 & & $\mathbf{0 . 8 3 0}$ \\
\hline
\end{tabular}

Table 2. Semi - Structured Interview Questions

\begin{tabular}{|l|l|}
\hline 1 & Does emotion influence memory in learning Mathematics? \\
\hline 2 & How to increase emotion that improves your memory in teaching Mathematics? \\
\hline
\end{tabular}

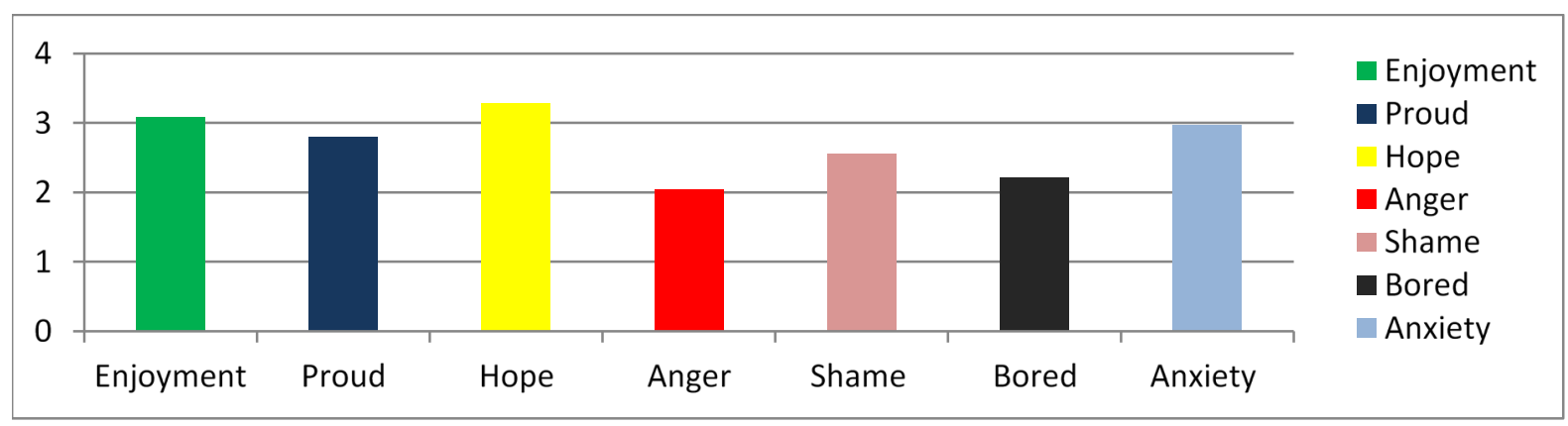

Figure 1. Descriptive Analysis of Students' Perception on Positive and Negative Emotions 




Figure 2. Correlations Between Components of Emotions and Memory in Learning Mathematics

Figure 2 indicates the correlations between components of emotions and memory in learning Mathematics. There are correlations for positive emotions which for positive emotions which are enjoyment $\left(r=.668^{*}, \mathrm{~N}=644\right.$, $\mathrm{p}$ $<.001)$, proud $\left(\mathrm{r}=.597^{*}, \mathrm{~N}=644, \mathrm{p}<.001\right)$ and hope $(\mathrm{r}$ $=.604 *, \mathrm{~N}=644, \mathrm{p}<.001)$ with memory. Findings indicated strong, positive correlations between enjoyment, proud, and hope and students' memory in learning Mathematics. However, the correlations are as follows: for negative emotions with the specific components of shame $(\mathrm{r}=-.513, \mathrm{~N}=644, \mathrm{p}<.001)$, anger $(\mathrm{r}=-.466$, $\mathrm{p}$ $<.001)$, boredom $(\mathrm{r}=-.488, \mathrm{~N}=644, \mathrm{p}<.001)$ and anxiety $(\mathrm{r}=-.493, \mathrm{p}<.001)$ with memory. Findings indicated strong, negative correlations between anger, shame, anxiety and boredom with students' memory in learning Mathematics. According to the findings, students indicated that they are more likely to have positive emotions compared to negative emotions in learning Mathematics. In other words, students with positive emotions tend to have an enhanced memory performance, while students with negative emotions tend to have a low memory performance in learning Mathematics.

The results show that positive emotions have a significant relationship with students' memory in Mathematics learning. In other words, a student who enjoys learning Mathematics influences their attention in teaching and learning process. They are also able to understand the content of the subject. This can ignite proud feeling for their achievement because they manage to solve mathematical problems. It will provide a positive experience for students in learning Mathematics and reduce negative perception towards Mathematics. Thus, it could improve students' cognitive processing especially the working memory. However, negative emotions could affect students' behavioural and psychological well-being because they are afraid of a dictating learning environment, panic to answer questions and shy to respond and engage in lessons. Reports from previous research $[8,20,26,31,34]$ are in line with the results of this study which explain that negative emotions particularly anxiety and shame provide negative experiences for students to learn. These negative experiences will affect students' ability to solve mathematical problems as well as their memory performance.

Besides, qualitative data indicated that participants' positive emotions can stimulate student to learn Mathematics. It can be concluded that 'emotions based teaching' can cultivate positive emotions in learning Mathematics. This is an effective method to attract students' attention and memorization during the teaching and learning process. Participants explained that when teachers are cheerful, able to engage students with humorous material and give positive reinforcement in the classroom, they feel a sense of belonging in the classroom. Therefore, they feel more excited to learn Mathematics. Moreover, participants expressed positive emotions such as enjoyment and hope which motivated their involvement in the learning process, made them more willing to participate in the learning activities, sparked their interest in solving problem in Mathematics as well as decreased their anxiety in learning Mathematics. Participants also expressed that teacher should embed positive emotions through the use of humour in teaching Mathematics, inspiring positive words and engaging students in classroom by asking their needs and emotions to improve students' memory in learning Mathematics

Therefore, those results strongly support the hypothesis that there is a correlation between positive emotion and memory in learning Mathematics. Besides, this result is also supported by literature from neuroscience research $[12,14,28,32]$ which said that positive emotions can influence memory in learning process. Brain research provides insight into how the brain unconsciously pays 
attention and memorizes in the process of learning information. When information enters our senses through the eyes and ears, the coded message is passed through the regions of the brain that can either expedite or block its progress. The thalamus processes the sensory input and determines whether it will be kept in temporary awareness or moved to the memory storage. If the input is processed as more than the transient awareness, it passes along the neurons in the amygdala which is a structure used for emotional memory processing. If negative emotions have overloaded the amygdala, it will block the passage of the data from getting into the memory. The amygdala interprets the information in order to determine the emotion that should be linked to the positive emotions or negative emotions in learning. All of the information will be transmitted to frontal cortex, the outermost, frontal area of the brain $[19,27,29]$. The frontal cortex processes the information and helps the brain to determine if it already knows something about the information that is being perceived. The brain does this in order to establish whether it needs to invest the energy on learning it or not. Then, the brain sends the information to hippocampus of the brain region which is essential for memory.

\section{Conclusions}

Emotions play a significant role in determining memory in learning. In this study, researchers had to identify the components of positive and negative emotions and its relationship with memory in learning Mathematics. The positive emotional components which consist of enjoyment, proud and hope showed that there were significant, positive correlations between the components of positive emotions. The findings also showed that students with high positive emotions have a positive relationship with learning memory. From a psychological view, students with emotional states indicate that students are interested in learning, engaged in the classroom and have a good perception of learning Mathematics. In general, the combination of neuroscience research and education is one of the efforts used to improve delivery system of education, thus enhancing students' emotions for learning. Although the network of disciplines between neuroscience and education is very complex, a comprehensive effort is required, as the results of channelling the knowledge can have a significant impact on improving teaching and learning practices in the classroom especially in developing students' emotions.

For future research, it is important to examine how students develop their emotions in learning Mathematics and its effect to memory using cross-sectional method. This research can understand and explore how emotions affect their behaviours. This research also suggests future studies to use Functional Magnetic Resonance Imaging (fMRI) tool to investigate the role of the amygdala in positive and negative emotions and how it distributed across wider neural networks particularly hippocampus for memory performance and prefrontal cortex for decision make and problem solving in learning Mathematics. This could yield valuable information for the prevention of negative emotions such as anxiety and the rest in the future and for the development of valid therapeutic intervention against negative emotions in learning Mathematics. In conclusion, this study emphasised that positive emotions when learning Mathematics are related to students' high levels of memory performance and negative emotions are related to students' low levels of memory performance. This understanding can encourage teachers to create an attractive environment that is compatible with the biological functioning of the students' brain. Thus, a fun learning environment may reduce students' negative emotions and could enhance their memory performance.

\section{Acknowledgments}

The authors would like to thank Universiti Kebangsaan Malaysia for funding this research using the grants with code numbers GG-2019-082 and GG-2017-019.

\section{REFERENCES}

[1] Fischer, K., W., Daniel, D., B., Immordino-Yang, M., H., Stern, E., Battro, A., Koizumi, H., "Why mind, brain, and education? Why now?" Mind, Brain, and Education, vol. 1, pp. 1-2, 2007.

[2] Zadina, J, "The emerging role of educational neuroscience in education reform", Psicologia Educativa, vol. 21, pp. 71-77, 2015.

[3] Muhammad Syawal A., Saemah R., Shahlan S., Abu Yazid A., B., "Connecting Neuroscience and Education: Insight from Neuroscience Findings for Better Instructional Learning", Journal for the Education of Gifted Young Scientists, vol. 7, no. 2, pp. 341-352, 2019. DOI:10.17478/jegys.559933

[4] Thomas, M., Ansari, D., Knowland, V, "Annual Research Review: Educational neuroscience: progress and prospects", Journal of child psychology and psychiatry, and allied disciplines, vol. 60, no. 4, pp. 477-492, 2019. https://doi.org/10.1111/jcpp.12973

[5] Stern E., Roland H. Grabner, Schumacher R, "Neuroscience and Education Added Value of Combining Brain Imaging and Behavioral Research", Zeitschrift für Psychologie, vol. 224, no. 4, 2016.

[6] Howard-Jones, "Neuroscience and education: Myths and messages", Nature reviews. Neuroscience, vol. 15, 2014. 10.1038/nrn3817.

[7] Beilock S. L., Maloney E. A, "Math anxiety: A factor in math achievement not to be ignored", Policy Insights from the Behavioral and Brain Sciences, vol. 2, pp. 4-12, 2015 
[8] Martínez-Sierra, G., "Students' emotional experiences in high school mathematics classroom." Konrad Krainer; Nad'a Vondrová. CERME 9, Proceedings of the Ninth Congress of the European Society for Research in Mathematics Education, Prague, Czech Republic, pp. 1181-1187, 2016.

[9] Sokolowski, H., Ansari, D., "Who Is Afraid of Math? What Is Math Anxiety? And What Can You Do About It?", Front. Young Minds, vol 5, pp. 57, 2017

[10] Immordino-Yang, M. H., Darling-Hammond, L., Krone, C. R., "Nurturing nature: How brain development is inherently social and emotional, and what this means for education." Educational Psychologist, vol. 54, no. 3, pp. 185-204, 2019. https://doi.org/10.1080/00461520.2019.1633924

[11] Vogel, S., Schwabe, L., "Learning and memory under stress: implications for the classroom", npj Science of Learning, vol. 1, pp. 16011, 2016. https://doi.org/10.1038 /npjscilearn.2016.11

[12] Kucian, K., McCaskey, U., O'Gorman Tuura, R., "Neurostructural correlate of math anxiety in the brain of children." TranslPsychiatry, vol. 8, pp. 273, 2018. https://doi.org/10.1038/s41398-018-0320-6

[13] Buckley, S., "Gender and sex differences in student participation, achievement and engagement in mathematics", Changing Minds: Discussions in neuroscience, psychology and education. Published by Australian Council for Educational Research, 2018 ABN 19004398145

[14] Suárez-Pellicioni, Núñez-Peña, \& Colomé, À., "Math anxiety: A review of its cognitive consequences, psychophysiological correlates, and brain bases.”, 2016.

[15] Effandi, Normalizam M. Z., Nur Amalina A., Ayu Erlina, "Mathematics anxiety and achievement among secondary school students", American Journal of Applied Sciences, vol 9, no. 11, pp. 1828-1832, 2012.

[16] Suppiah, Rengasamy, K., Vishananthini, Charles, "Analisis Pengajaran Guru dalam Mata Pelajaran Matematik ke Arah Aplikasi Kognisi dalam Kurikulum Standard Sekolah Rendah Melalui Kaedah Hermeneutik", Journal of Social Science, ISSN 2289-9391 vol. 2, pp. 31-4, 2016.

[17] Maloney, E. A., Ramirez, G., Gunderson, E. A., Levine, S. C., Beilock, S. L., "Intergenerational effects of parents' math anxiety on children's math achievement and anxiety", Psychol. Sci, vol. 26, pp. 1480-1488, 2015. doi: $10.1177 / 0956797615592630$

[18] Jackson, K., "Math anxiety and attitudes in pre-service elementary teachers (thesis and dissertation)." Rowan University, Glassboro, $\mathrm{Nj}$, https://rdw.rowan.edu/etd/409, 2015 (accessed Aug. 13, 2019).

[19] Dettweiler, U., Becker, C., Auestad, B. H., Simon, P., Kirsch, "Stress in School. Some Empirical Hints on the Circadian Cortisol Rhythm of Children in Outdoor and Indoor Classes." Int. J. Environ. Res. Public Health, vol. 14, pp. 475, 2017

[20] Peixoto, F., Sanches, C., Mata, L., Monteiro, V., "How do you feel about math?": Relationships between competence and value appraisals, achievement emotions and academic achievement. European Journal of Psychology of Education, vol. 32, pp. 385-405, 2017.

[21] Shafie D., Ramli B., Roslan B., Shahandri G., "Pengaruh
Amalan Jenaka Terhadap Pengajaran dan Pembelajaran Murid", Asia Pasific Journal of Educators. vol. 26, no. 1, pp. 125-144, 2011.

[22] Yuan, R., Lee, I., "I need to be strong and competent': a narrative inquiry of a student-teacher's emotions and identities in teaching practicum”, Teach. Teach, vol. 22, pp. 819-841, 2016. doi: 10.1080/13540602.2016.1185819

[23] Arsaythamby V., Shamsuddin M., "Hubungan Sikap, Kebimbangan dan Tabiat Pembelajaran dengan Pencapaian Matematik Tambahan", Asia Pacific Journal of Educators and Education, vol. 26, no. 1, pp. 15-32, 2011

[24] Puteh, Khalin, "Mathematics Anxiety and Its Relationship with the Achievement of Secondary Students in Malaysia", International Journal of Social Science and Humanity, vol. 6, no. 2,2016

[25] Benno, Bruce, Sumantra, "Stress, memory and the amygdala." Nature Reviews Neuroscience, vol. 10, pp. 423433, 2-1, 2009.

[26] Pekrun, Goetz, Frenzel, Raymond, Perry, "Measuring emotions in students' learning and performance: The Achievement Emotions Questionnaire (AEQ)", Contemporary Educational Psychology, vol. 1, pp. 36-48, 2011.

[27] Baixauli E., "Happiness: Role of Dopamine and Serotonin on Mood and Negative Emotions", Emerg Med (Los Angel) 7: 350, 2017 doi: 10.4172/2165-7548.1000350

[28] Sandi, C., Haller, J., "Stress and the social brain: behavioural effects and neurobiological mechanisms", Nature Reviews Neuroscience, vol., 16, pp. 290-304, 2015

[29] Lyons, I. M., Beilock, S. L., "Mathematics anxiety: Separating the math from the anxiety", Cerebral Cortex, vol. 22, no. 9, pp. 2102-2110, 2012.

[30] Breedlove, Watson, Rosezweig, "Biological Psychological; An Introduction to Behavioral, Cognitive and Clinical Neuroscience”, Sinauer Associatesm Inc. Publisher, 2010.

[31] Swanson, H. L., "Working memory, attention, and mathematical problem solving: A longitudinal study of elementary school children", Journal of Educational Psychology, vol. 103, no. 4, pp. 821-837, 2011 doi: $10.1037 / \mathrm{a} 0025114$

[32] Hidalgo, V., Pulopulos, M., Salvador, A., "Acute psychosocial stress effects on memory performance: Relevance of age and sex", Neurobiology of Learning and Memory Journal., vol. 157, pp. 48-60, 2018

[33] Geurten, M., Majerus, S., Lejeune, C., Catale, C., "Questionnaire of Memory (Q-MEM): A new measure of everyday memory functioning in school-age children", Applied Neuropsychology: Child, vol. 7, pp. 1-8, 2016. 10.1080/21622965.2016.1239201

[34] Passolunghi, M., Caviola, S., De Agostini, R., Perin, C., Mammarella, I, "Mathematics Anxiety, Working Memory, And Mathematics Performance in Secondary-School Children", Journal of Clinical and Experimental Neuropsychology, 42/7, 2016. DOI: 10.3389/Fpsyg.2016.0 0042 . 
[35] Ritchie, J., Spencer, L., "Qualitative data analysis for applied policy research" by Jane Ritchie and Liz Spencer in A. Bryman and R. G. Burgess [eds.] "Analyzing qualitative data", pp.173-194, 1994.

[36] Galletha, A., "Mastering the Semi-Structured Interview and Beyond", New York: New York University Press, 2013. 244 pp. ISBN: 9780814732939

[37] Muhtarom, Nizaruddin, Sutrisno, Pathuddin, "Capturing Prospective Teachers' Beliefs about Mathematical Problem Solving", Universal Journal of Educational Research, vol. 8, no. $5, \quad$ pp. $2100-2107,2020$. DOI: 10.13189/ujer.2020.080548.

[38] Tall, D., "Mathematics and Emotion. In How Humans Learn to Think Mathematically: Exploring the Three Worlds of Mathematics" Learning in Doing: Social, Cognitive and Computational Perspectives, Cambridge: Cambridge University Press, 2013, pp. 118-132.doi:10.1017/CBO9781 139565202.010

[39] Dror O. E., "The Cannon-Bard Thalamic Theory of Emotions: A Brief Genealogy and Reappraisal", Emotion Review, vol. 6, no. 1, pp. 13/20, 2014. doi: $10.1177 / 1754073913494898$ 